\title{
EXPERT CRISIS CENTRE AS A MECHANISM OF SUPPORT TO THE ENTERPRISE CRISIS MANAGEMENT
}

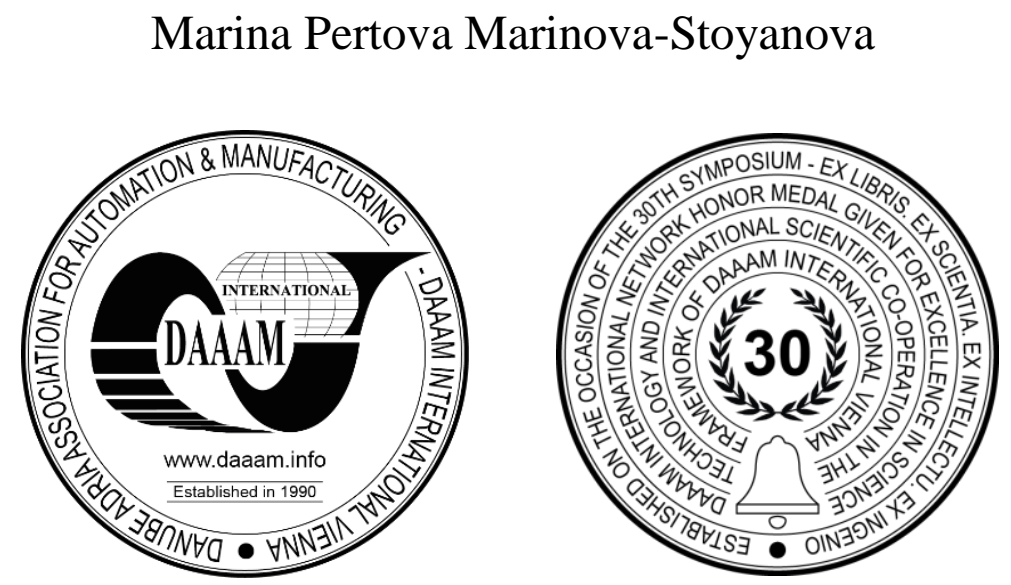

This Publication has to be referred as: Stoyanova-Marinova, M[arina] (2020). Expert Crisis Centre as a Mechanism of Support to the Enterprise Crisis Management, Proceedings of the 31st DAAAM International Symposium, pp.06770682, B. Katalinic (Ed.), Published by DAAAM International, ISBN 978-3-902734-29-7, ISSN 1726-9679, Vienna, Austria

DOI: $10.2507 / 31$ st.daaam.proceedings.094

\begin{abstract}
The primary focus of the present paper is on the effective implementation of a proactive anti-crisis management (PAM) system within a given enterprise. Proposed is a matrix for a successful prediction of a probability of crisis occurrence within the enterprise on the basis of the experts' weak signal assessments. A structural and functional model of an enterprise's expert crisis centre has been improved and specially adjusted as a means of supporting the decisions for crisis prevention in PAM. Considered are the successive stages in the process of ECC management decision-making during a crisis at a Bulgarian manufacturing enterprise.
\end{abstract}

Keywords: proactive anti-crisis management; management decision-making; matrix of crisis conditions; expert crisis centre; manufacturing enterprise.

\section{Introduction}

Currently, a large number of manufacturing enterprises are struggling for their economic survival, largely due to the lack of constructive management decisions to effective and efficient crisis prevention. This, in turn, necessitates the swift implementation of alternative instruments and mechanisms to allow the accomplishment of constant monitoring for weak signal detection seen as indicative of the occurrence of crisis arising from the surrounding environment; appropriate predictions as to the gradual evolvement of the situation as determined by the strength of the signal; proactive preventive measures, within the enterprise, for crisis avoidance; decisions towards successfully overcoming and eliminating a crisis situation. The main objective of the paper is to propose an instrument to facilitate the respective managers in their managerial decision-making in situations of crises and help them identify the correct option as to their potential elimination through the introduction of an Expert Crisis Centre (ECC).

To fulfil this aim the following research tasks have been resolved:

- Introduction of a proactive anti-crisis management system for preventing the development of a crisis situation.

- Forecasting the development of a possible crisis situation within the enterprise;

- Establishing the ECC's organizational - functional structure

- Creating a system of preparation and decision-making within the enterprise's expert crisis center. 
The crisis is viewed as a process that would worsen its distinctive features over time, has negative side effects and requires prompt and adequate resolutions to its prospective prevention, mitigation and recovery. Analyses indicate that the traditional instruments [5], [4], most commonly used over the past few years fail to provide an objective assessment, by the mere fact that they are designed for a relatively stable economy.

\section{Proactive anti-crisis management system of the enterprise.}

The concept of crisis management (CM) is based on G. Kristek's model of the four stages - potential, latent, acute and chronic. In view of the stages of an economic crisis within the manufacturing enterprise, the pro-active anti-crisis management directs its activities to the first two stages - potential and latent (hidden) stages, in which the crisis has yet to develop. CM is presented as a system built upon two subsystems - proactive CM and reactive CM [6]. The main objective of the PAM system is - crisis avoidance through proactive activities in response to signals of potential adverse effects of the external and internal environment of the enterprise.

\section{Forecasting the development of a possible crisis situation within the enterprise itself.}

The identification of the crisis is a crucial stage for the successful ME management. It is of utmost importance, therefore, to be able to discern the signals, to identify the underlying causes and related signs prior to the onset of the crisis. The signals themselves according to the strength of their effect upon the enterprise can be weak, moderate, or strong. Furthermore, it is the weak signals that should be more extensively explored since they are the ones regarded as a pre-emptive indicator for evaluation and prediction of negative changes, recorded in real time. Scanning and diagnostics of the weak signals caused by the internal and external environment is carried out by the method of expert evaluation.

\subsection{Expert evaluation method [8].}

The method of expert evaluations is a modern control tool for obtaining quantitative assessment of indicators, other than the financial ones, that are distinctive of ME. The experts having been selected, particular premises (expert crisis centre) should be set apart, allowing the experts to work together in a team and not influenced by any subjective factors. Expert survey cards will be developed, stating briefly those factors that are critical for the success of the enterprise under consideration and their indicators for the purposes of monitoring. Each expert is expected to provide their own assessment as regards the impact strength of the signal generated by the external and internal environment upon the normal working state of the enterprise. The rating scale ranges from 0 (no signal) to 5 (very strong).

The subsequent analysis of the results of the expert evaluations will determine - the arithmetic mean value of the signal $\left(\mathrm{S}_{\mathrm{i}}\right)$; the authenticity of the threat signal $\left(\mathrm{T}_{\mathrm{S}}\right)$; the intensity of the threat signal (I ); the magnitude of the threat signal (M). The next stage in assessing the signals from the internal and external environment is to determine the relative weights of the related subsystems and factors, through the so-called "method of direct indicator ranking" [3].

\subsection{Author's matrix of the crisis situations within the enterprise}

The group method should be applied to determine the rating scales in the matrix. With it, the number of the groups (k) that correspond to the four stages of the crisis is determined in advance, preceding the calculation of the width of the interval (h), as a relative difference between the smallest and the largest possible values of the measured signal/sign. The application of the arithmetic group method, along with the already adopted Kristek's model for the stages of the crisis process, is at the very basis for determining the scale of the predicted values of the impact of the threat signals upon the enterprise's activities, proportional to the four stages of the crisis (Table 1).

\begin{tabular}{|c|c|c|c|c|}
\hline № & $\begin{array}{c}\text { Numeric } \\
\text { distribution } \\
\text { according to the } \\
\text { stages of the crisis }\end{array}$ & $\begin{array}{c}\text { Scale of intensity and } \\
\text { aggregate values of the } \\
\text { signals received }(\%)\end{array}$ & $\begin{array}{c}\text { Status of the } \\
\text { signals, received in } \\
\text { the process of } \\
\text { monitoring }\end{array}$ & $\begin{array}{c}\text { Predictable } \\
\text { probability of crisis } \\
\text { occurrence }\end{array}$ \\
\hline 1. & Up to 1,25 & Up to 25 & Weak & Insignificant \\
\hline 2. & $1,25-2,5$ & $25-50$ & Strong & Low \\
\hline 3. & $2,5-3,75$ & $50-75$ & Very strong & High \\
\hline 4. & $3,75-5,00$ & $75-100$ & & \\
\hline
\end{tabular}

Table 1. Predicted scale of the threat of signal impact and the probability of crisis occurrence within the enterprise

The author's matrix of the crisis conditions is built upon the Asaul's matrix [1] and the matrix of the consequences and possibilities [9]. It has been constructed on the basis of the likelihood of a crisis occurrence, measured along the horizontal axis, and the threat of signal impact upon the ME activity, along the vertical axis (fig. 1.) 
Marked along the ordinate is the obtained value of the intensity of the detected signals, which determine the threat of their impact on ME activity. It also determines the depth of manifestation (referring to the possibility or potential for overcoming) of the crisis occurring within ME, i.e. it takes into account the dynamics of the development and the expansion or spread of the crisis. Recorded further along the abscissa is the probability of crisis occurrence. In addition, the calculated average aggregate value of the expert evaluations for the identified indicators is projected to facilitate the detection of signals and the establishment of the breadth of the consequences of a crisis occurrence.

The matrix of the crisis conditions makes it possible for the management to predict the likelihood of a crisis occurrence within a given ME. Accordingly, the diagnostics of weaker signals is decisive for the timely threat detection, for the prevention of their adverse effects upon the enterprise's activities and for the adoption of measures for crisis prevention and its non-development within the ME.

Observing the changes discussed above produced is the following distribution by zones:

- Zone $Z_{1}, Z_{2}, Z_{5}$ - zone of potential crisis;

- Zone $Z_{3}, Z_{4}, Z_{6}, Z_{7}, Z_{9}, Z_{10}, Z_{13}$ - zone of latent crisis;

- Zone $Z_{8}, Z_{11}, Z_{12}, Z_{14}, Z_{15}$ - zone of acute crisis;

- Zone $Z_{16}-$ zone of chronic crisis.

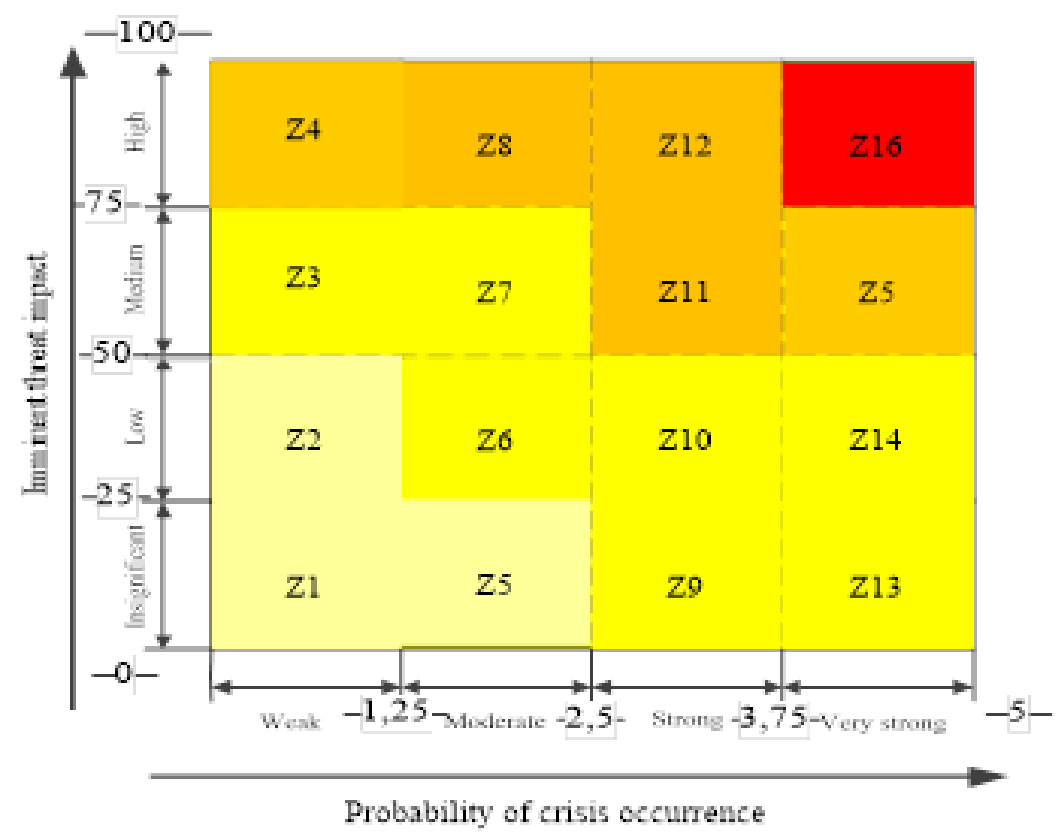

Fig. 1. Matrix of crisis conditions

Maintaining constant monitoring of the environment and the adoption of pre-emptive preventive measures to eliminate a crisis occurrence across the enterprise is a feature of the ECC.

\section{Organizational - functional structure of ECC}

The Expert Crisis Centre (ECC) is defined as innovative set of methodological, information, technology and software tools designed to support the work of the analysts and managers when making decisions about the occurrence of crisis situations in the enterprise and their possible prevention [2]. The presented structural-functional model of an expert crisis centre facilitates the work of experts, analysts and managers in making decisions as regards the occurrence of crisis situations in the enterprise and their prevention (fig.2).

The institutionalisation of the ECC within the enterprise requires the completion of the following stages:

- Laying down basic principles for establishing the necessary requirements for the institutionalization of such a centre;

- Formulation of methodological bases for ECC's structural and functional components;

- Assemblage of the equipment (where necessary and in the lack of software information - analytical system). Installation of information systems, in the absence of such systems;

- System for preparation and decision-making within the ECC;

- Staff training. 


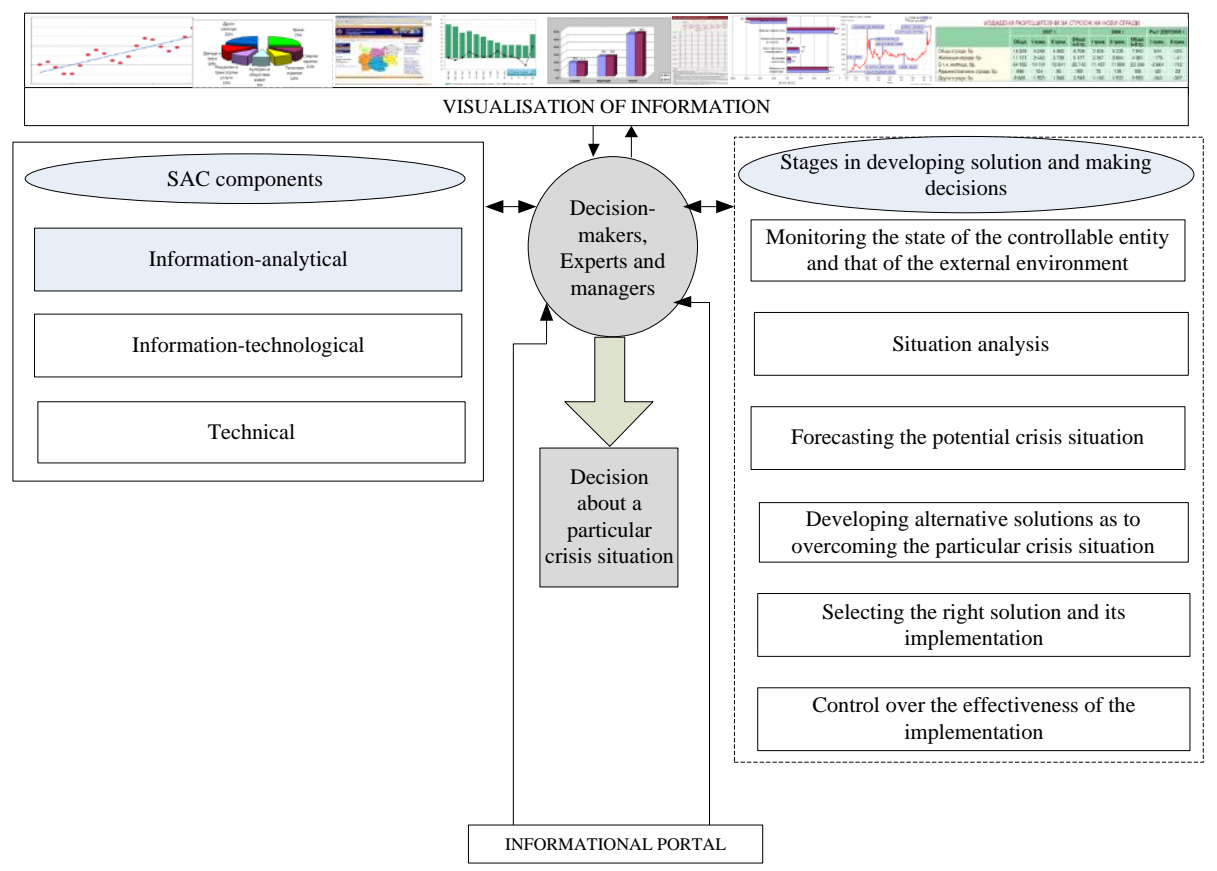

Fig. 2. Structural-functional model of an expert crisis centre [7]

\section{System of preparation and decision-making (SPDM) within the ECC .}

The main objective of the paper is to develop an algorithm for the smooth functioning of the system for preparation and decision-making (SPDM) which appears to be the most important stage in the process of resolving situational tasks, identifying the signals and facilitating all the systems for successful interaction, response and prevention of a possible crisis situation. It is, therefore, based on the entire arsenal of information flow processing tools, technologies for easy access to the information and analytical systems, instrumental modelling tools and methods for visualisation. An important SPDM feature is the individual expert's approach, in addition to the analytical reading of the information provided in the selection of information resources at each stage of the decision-making process. When making decisions, the sample dataset is summarized as follows:

$<\mathrm{X}, \mathrm{Z}, \mathrm{F}, \mathrm{U}, \mathrm{G}>\min (\max ) \mathrm{K}$, where [8]:

$\mathrm{X}$ - Multiple options of admissible alternatives in decision-making;

Z - Threat;

$\mathrm{F}$ - Evaluation of the multitude of admissible alternatives over a set of multiple criteria;

$\mathrm{U}-$ Variations of decisions;

$\mathrm{G}$ - A system of the decision-makers' individual preferences;

$\mathrm{K}-$ Selection of criteria.

This is the model that has been successfully introduced in a Bulgarian manufacturing enterprise and the results obtained demonstrate the effectiveness of the practical application of the management control mechanisms with the purpose of improving $\mathrm{CM}$.

\section{Practical implementation of the ECC in a Bulgarian enterprise.}

Nevi Tex Group Ltd works mainly on a toll manufacturing arrangement, providing its clients with full- cycle services. The main product categories are women's and men's shirts, blouses, trousers, pyjamas intended for export to the European market. After the structural establishment of the ECC to support the functioning of the PAM system was pursued by the specification of the tasks. Stage 1: Formation of basic principles for establishing the Centre's institutionalisation requirements. The principles applied for the ECC establishment are consistency in communication, restructuring and timeliness of the management process, unification of standards and reports, visualisation and raising the awareness in the event of deviations and reliability of the technical equipment. Stage 2: Formulation of methodological bases for ECC's structural and functional components.

Use was made of the following instrumental and modelling tools:

- Information and analytical accounting system „, -,„, management system, Norma management; Excell, etc.;

- Intellectual potential of all management levels and functional areas of management;

- A single unified screen for data flow visualisation allowing for the information to be displayed graphically; 
Stage 3: Installation of equipment (if necessary and where there is no software information and analytical system). Introduction of information systems, in the absence thereof. There is a separate room for deploying the panel of experts working at the centre. Each of them is presented with technologies equipped with the necessary software and accessible real-time information flows. Available, in addition, is a single unified screen for accessing and viewing the information. Stage 4: Preparation and decision-making system within the ECC

- Monitoring and scanning the influence of external and internal factors.

The expert toolkit for examining and analysing the impact of the external and internal factors measures every change in these indicators through a "linguistic assessment scale". The experts assess the negative impact of the signals for each of the indicators acting upon the activities of the surveyed enterprise. The scoring of the signal strength is assigned on a five-point scale from 0 to 5 , with the assessment 5 being granted when the threat of negative impact of the specified indicator is very strong, 4 - strong, 3 - moderate, 2 - weak, 1 - very weak and 0 is given when there is no signal for immediate threat. The research carried out into the impact of the factors from the internal environment leads to the conclusion that the highest level of threat from a crisis occurrence is manifested in the factors that relate to innovation and investment, personnel, production along with the technico-technological ones.

- Forecasting the development of a possible crisis situation

In order to predict the development of the enterprise and the possibility of a crisis occurrence, calculated are the mean values of the magnitude of the internal $(M=67,4)$ and the external environment $(M=58,5)$. The obtained values are measured along the ordinate and correspond to the threat of impact. The abscissa conveys the result obtained from the mean value of the expert assessments as to the impact of the weak signals from the internal $\left(S_{i}=2\right)$ and the external $\left(S_{i}=1,83\right.$ ) to the enterprise environment by which the probability of a crisis occurrence is to be determined. Projecting the data received in the two-dimensional matrix of crisis conditions, the enterprise appears to fall within the quadrant $Z_{7}-$ a zone of latent crisis. It is therefore necessary to take preventive measures to overcome the crisis situation and prevent its expansion across the enterprise.

- Selection of alternative solutions, management decision making and control

The explicit signals - the threat arising from the internal factors point to the staff turnover, low-skilled employees, unused production capacities, reduced volume of orders, age structure of machinery and equipment. Threats triggered by the external environment refer to - increase in the minimum wage rates, the age structure of the population (ageing), the level of education - qualification, the burden of social security contributions at the expense of the employer, international cooperation,the impact of the main competition at home and abroad. Concrete proposals have been made to Nevy Tex Group Ltd as to the measures that need to be taken in order to prevent the development of the crisis within the enterprise [10]. In the wake of the package of pro-active measures that have been introduced, the profit of the enterprise increased significantly, to achieve a growth of $230 \%$ in relative value compared to the previous reporting period. This is also due to the accomplished optimisation of the external service costs by $11 \%$, representing about $50 \%$ of the company's operating costs. Stage 5: Staff training

\section{Conclusion}

The conducted research gives reasonable grounds for asserting the conclusion that successful crisis management within the enterprise is contingent upon the timely identification of the signals for objective assessment and the consequences of the crisis. Successful crisis management is feasible through the introduction of ECC in the enterprise. The main contribution of the institutionalisation of the ECC in the ME is the real-time monitoring and diagnostics of signals originating from the external and internal environment. The quantitative assessment of the signals has been carried out through a modified algorithm for expert assessments of the early warning weak signals of an emerging crisis threat. The degree of the threat of a crisis occurrence and the prediction of the enterprise's development were estimated through the author's « matrix of the crisis conditions». All in all, the operation of the center should be carried out through the integration of innovative set of information- analytical, information-technical and technical components, separated in a single unified unit, providing strength and support to the experts' activities.

On the whole, the ECC introduction in Bulgarian enterprises has also facilitated the management in its swift decision-making as to the measures that should be taken in order to prevent the likely development of an impending crisis. Moreover, the adopted preventive measures proved to be beneficial for the stabilisation and improvement of the enterprise's financial situation. The subsequent research goals and objectives are aimed at developing a strategy and alternative range of preventive and protective measures to an appropriate crisis situation response.

\section{References}

[1] Asaul A. N.; I. P. Knyaz ; Ju. V. Korotaeva. (2007). Theory and Practice of the decision making in the conditions of crisis of the organizations, ISBN 978-5-91460-003-4, St. Petersburg; Асаул, А.Н., И.П. Княз. , Ю. В. Коротаева, (2007). Теория и практика принятия решений в условиях кризиса организаций, ISBN 978-591460-003-4, Санкт-Петербург 
[2] Demidov, N.N; Ilyin; N. I., Novikova, E.V. (2011). Situational Centre- Experience, Status and Development Trends, Alpha Press, ISBN 978-5-902750-18-5, Moscow; Демидов, Н. Н.; Ильин,Н.И.; Новикова,Е.В., (2011). Ситуационные центры - Опыт, состояние,тенденции развития, Альфа-Пресс, ISBN 978-5-902750-18-5, Москва

[3] Georgiev, V., K. (1998). Possibility of the group approach in decision making and acceleration of Innovation, ISBN - 954-20-0075-8, Varna , Bulgaria; Георгиев, В., К., (1998), Възможност на груповия подход при вземане на решения и ускоряване на иновациите", ISBN - 954-20-0075-8, Варна, България

[4] Kaplan, R.S.; Norton, D.P. (2001). The strategy-focused organisation, ISBN-10: 9783791018027, ISBN-13: 9783791018027, Stuttgart, Germany Publisher Schäffer Poeschel Verlag; Kaplan, R.S.; Norton, D.P., (2001) Die strategiefokussierte Organisation, ISBN-10: 9783791018027, ISBN-13: 978-3791018027, Schäffer Poeschel, Sttutgart

[5] Simon, A. (2015). Crisis Management Strategy - Competition and Change in Modern Enterprises, ISBN-13: 9781138183704, 29 West 35th Street, New York, NY 10001, First published 1993 by Routledge, ISBN-10: 1138183709

[6] Lesidrenska, Sv., M. Marinova-Stoyanova. (2014). Proceedings of the 5th International Congress of Controlling, 2014, A concept of the enterprise proactive anti-crisis management system, Moscow, Russia

[7] Lesidrenska, Sv.; M. Marinova. (2015). Regional scientific-business conference, leadership \& management: government, enterprise, entrepreneur, Institutionalisation of the enterprise proactive anti-crisis management system through the development of situationanalytical centres, December 2010

[8] Marinova-Stoyanova, M. (2019). Application of expert evaluation in the proactive anti-crisis management of the manufacturing enterprise. Controlling Journal, №3 (73) (2019), p. 2-9

[9] BDS (Bulgarian Institute of Standardization) :ISO, 31000:2011, (2011) February, БДС ISO 31000:2011, (2011) Февруари

[10] Marinova - Stoyanova, P., M. (2019). Opportunities to improved anti-crisis management of production enterprises through the application of control mechanisms, PhD. Dissertation, Technical University of Varna, Varna, Bulgaria Маринова-Стоянова, П., М. (2019). Възможности за усъвършенстване на антикризисното управление на производствените предприятия посредством приложението на контролингови механизми, Дисертация, Технически университет Варна, гр. Варна, България. 